\title{
Adaptation of Lettuce mosaic virus to Catharanthus roseus Involves Mutations in the Central Domain of the VPg
}

\author{
Laurence Svanella-Dumas,, ${ }^{1,2}$ Eric Verdin, ${ }^{3}$ Chantal Faure, ${ }^{1,2}$ Sylvie German-Retana, ${ }^{1,2}$ Patrick Gognalons, \\ Jean Luc Danet, ${ }^{1,2}$ Armelle Marais, ${ }^{1,2}$ and Thierry Candresse ${ }^{1,2}$ \\ 'UMR 1332 Biologie du Fruit et Pathologie, INRA, CS 20032, 33882 Villenave d'Ornon Cedex, France; ${ }^{2}$ UMR 1332 Biologie \\ du Fruit et Pathologie, Université de Bordeaux, CS 20032, 33882 Villenave d'Ornon Cedex, France; ${ }^{3}$ Unité de Pathologie \\ Végétale, INRA, Domaine St Maurice, BP 94, 84143 Montfavet cedex, France
}

Submitted 28 November 2013. Accepted 3 January 2014.

An isolate of Lettuce mosaic virus (LMV, a Potyvirus) infecting Madagascar periwinckle (Catharanthus roseus) was identified and characterized by Illumina deep sequencing. LMV-Cr has no close affinities to previously sequenced LMV isolates and represents a novel, divergent LMV clade. Inoculation experiments with other representative LMV isolates showed that they are unable to infect $C$. roseus, which was not known to be a host for LMV. However, three $C$. roseus variants of one of these isolates, LMVAF199, could be selected and partially or completely sequenced. These variants are characterized by the accumulation of mutations affecting the $\mathrm{C}$-terminal part of the cylindrical inclusion (CI) helicase and the central part of the VPg. In particular, a serine to proline mutation at amino acid 143 of the VPg was observed in all three independently selected variants and is also present in the $\mathrm{LMV}-\mathrm{Cr}$ isolate, making it a prime candidate as a host-range determinant. Other mutations at VPg positions 65 and 144 could also contribute to the ability to infect $C$. roseus. Inoculation experiments involving a recombinant LMV expressing a permissive lettuce eukaryotic translation initiation factor 4E (eIF4E) suggest that eIF4E does not contribute to the interaction of most $\mathrm{LMV}$ isolates with $C$. roseus.

Lettuce mosaic virus (LMV), a member of the genus Potyvirus, is a pathogen of major significance for lettuce crops worldwide (Dinant and Lot 1992; German-Retana et al. 2008a). Like many other potyviruses, LMV has a relatively narrow natural host range, but a broader range of hosts have been identified through artificial inoculation experiments (Dinant and Lot 1992; Horvath 1980; Le Gall 2003). Like lettuce, its most important host, most hosts of LMV belong to the Asteraceae family. A few other susceptible species have been identified in various plant families, including the Chenopodiaceae (several

Nucleotide sequence data is deposited in the GenBank database under accession number KF268956.

Corresponding author: T. Candresse; Telephone: +33-5-57-12-23-89; Fax: +33-5-57-12-23-84; E-mail: tc@bordeaux.inra.fr

* The $\boldsymbol{e}$-Xtra logo stands for "electronic extra" and indicates that two supplementary tables and one supplementary figure are published online.

This article is in the public domain and not copyrightable. It may be freely reprinted with customary crediting of the source. The American Phytopathological Society, 2014.
Chenopodium species, spinach), Cruciferae (Shepherd's purse, Arabidopsis), Leguminosae (pea), Solanaceae (Nicotiana benthamiana), Malvaceae, Primulaceae, Caryphyllaceae, Geraniaceae. It is not known to infect members of the Apocynaceae family such as the periwinckles (Vinca spp.) or the Madagascar periwinckle (Catharanthus roseus [L.] G. Don.).

The emergence of novel diseases or of novel pathogens is a major concern for public health and for agricultural production (Anderson et al. 2004; Woolhouse et al. 2005). Virus emergence is a complex phenomenon that may involve various causes, alone or often in combination, such as ecological changes in the biotic or abiotic environment or genetic changes in one or more hosts or in viral populations (Anderson et al. 2004; Jones 2009; Parrish et al. 2008). In particular, the ability to replicate and colonize efficiently a new host can have a major impact on the development of novel viral epidemics.

In the case of potyvirus-plant interactions, although much information has been obtained on the identity of viral resistancebreaking determinants, in particular, when it comes to widespread eukaryotic translation initiation factor 4E (eIF4E)mediated resistance (Abdul-Razzak et al. 2009; Ayme et al. 2006; Borgstrom and Johansen 2001; Moury et al. 2004), there is, to date, little information about viral host-range determinants. The clearest example of such a determinant is the demonstration that a single amino acid, Lys27, of the protease domain of the NIa protease determines the ability of Papaya ringspot virus isolates to infect papaya (Chen et al. 2008). Likewise, the $\mathrm{P} 3$ protein-coding region has been shown by reverse genetics to be an important determinant of the ability of Turnip mosaic virus (TuMV) to infect Brassica or Raphanus spp. hosts (Suehiro et al. 2004). On the other hand, a more detailed study involving host-adaptation through serial passaging failed to identify mutations systematically associated with TuMV adaptation to Raphanus sativus, but mutations in the P1, P3, cylindrical inclusion (CI), and VPg were observed in several independently adapted viral lineages (Tan et al. 2005). Other regions shown or suspected in various studies to be involved in potyvirus adaptation to their host plants include the $\mathrm{P} 1$ protein (Carbonnel et al. 2012; Salvador et al. 2008b), the P3 and 6K1 region (Salvador et al. 2008a), the NIb (Wallis et al. 2007), and the CP N-terminus (Salvador et al. 2008a; Tatineni et al. 2011). Although the border between these two aspects can be hard to pinpoint, in many of these studies, the identified viral determinants more likely contributed to adaptation to a plant species that was already a host for the virus analyzed than the gain of a novel host species. 
In the present work, we describe and characterize an isolate of LMV associated with a novel host, the Madagascar periwinckle, as well as adapted variants that efficiently accumulate and spread in this plant and are derived from an isolate from lettuce, LMV-AF199. Complete or partial sequencing of the genome of these variants suggest that the viral VPg plays a major role in determining the ability of LMV to colonize $C$. roseus.

\section{RESULTS}

\section{Identification and characterization of an LMV isolate infecting Catharanthus roseus.}

Madagascar periwinckle plants with unusual, virus-like symptoms were identified among plants grown from seeds in a glasshouse in Bordeaux. The symptoms involved deformation and dark- and light-green sectoring of the leaves along major veins and a modification of flower morphology, with more slender and no longer overlapping petals (Supplementary Fig. 1). Those symptoms are essentially similar, with the exception of the flower breaking symptoms, to those recently described in Brazil for a novel potyvirus unrelated to LMV (Maciel et al. 2011). Initial efforts to characterize a virus in the affected plants involved both electron microscopy, which yielded potyviruslike particles (not shown), and mechanical transmission to a range of herbaceous hosts (Table 1). Identification of the virus involved as LMV, a well-known potyvirus, was finally obtained using both LMV-specific serological detection (Candresse et al. 2007; Dinant and Lot 1992) and LMV-specific polymerase chain reaction (PCR) amplification of a short genomic region overlapping the end of the $\mathrm{NIb}$ gene and the hypervariable $\mathrm{N}$ terminal region of the coat protein gene (Revers et al. 1997a) (results not shown).

Inoculation of lettuce varieties carrying various alleles of the mol resistance gene (Nicaise et al. 2003) demonstrated that, while this isolate readily infected plants carrying the $m o l^{\circ}$ susceptibility allele, it was unable to break the resistance conferred by the $\mathrm{mol}^{l}$ or $\mathrm{mol}^{2}$ resistance alleles (results not shown).

A full-length genomic sequence was obtained for this LMV isolate (LMV-Cr for Catharanthus roseus) through the multiplexed Illumina GAIIx sequencing of cDNAs obtained by whole-genome random amplification of immunocaptured particles. Of a total of 302,323 reads obtained for that sample (100 bp paired end sequencing, yielding $72 \mathrm{nt}$ of sequence after trimming of the amplification/tagging adapters), a total of 16,542 LMV-specific reads were obtained (5.5\% of reads), affording an average genome coverage of $118 \times$. The assembled reads yielded a large scaffold covering the whole LMV genome with the exception of the extreme $5^{\prime}$ end. This scaffold was partially resequenced, targeting regions of low coverage, which were amplified using primers specifically designed from the scaffold sequence (Supplementary Table S1). All resequenced regions were found to be $100 \%$ identical to the assembled scaffold, validating the genomic sequence thus generated.

The genome of the LMV-Cr isolate thus determined misses only the $14 \mathrm{nt}$ at the extreme $5^{\prime}$ end and has been deposited in the GenBank database under accession number KF268956. It is strictly co-linear with the complete LMV sequences available in GenBank, with the exception of the deletion of a $\mathrm{C}$ at position 9,908 in the $3^{\prime}$ noncoding region. This genome shows an overall $85.5 \%$ nucleotide identity with the closest LMV isolate in the GenBank database, i.e., LMV-0 (X97704, Revers et al. 1997b), showing $93.2 \%$ identity when the encoded viral polyproteins are compared. This genomic sequence does not show any obvious specificities, as all conserved motives typical of potyviruses could readily be identified, including the DAG aphid transmission triplet in the capsid protein. An analysis of individual proteins showed, as expected, that the P1 protein is the most divergent (only $78.7 \%$ identity), followed by the P3 and VPg proteins, which show respectively 88.6 and $92.7 \%$ with the corresponding proteins of LMV-0. All other proteins showed between 94.2 and $97.5 \%$ conservation. A phylogenetic analysis performed using the sequence of the coat protein gene of LMV-Cr and of representative LMV isolates from the GenBank database confirms that LMV-Cr has no known close counterpart and is, therefore, found at the extremity of a long branch (Fig. 1).

\section{Adaptation to Catharanthus roseus of the LMV-AF199 isolate.}

As $C$. roseus was not reported as a host for LMV, we then evaluated the ability of other LMV isolates to infect this host. Three lettuce isolates, the reference LMV-0 isolate (Revers et al. 1997a and b) and two mol-breaking isolates LMV-E (Revers et al. 1997a and b) and LMV-AF199 (Krause-Sakate et al. 2002) were thus mechanically inoculated to young $C$. roseus plants in parallel to LMV-Cr. All the plants inoculated with $\mathrm{LMV}-\mathrm{Cr}$ developed symptoms and reverse transcription (RT)-PCR at 3 to 5 weeks postinoculation showed readily detectable virus accumulation in several independent inoculation assays. In contrast, no symptoms and no viral accumulation could be observed by RT-PCR at the same time points in the plants inoculated with the other three LMV isolates (using a minimum total of 25 plants in several independent inoculation assays, not shown), indicating that the ability to infect $C$. roseus is not a general feature of LMV isolates but a specific property of LMV-Cr.

Some of the inoculated C. roseus plants were further kept in a greenhouse and monitored for several months for symptom development. Approximately 6 months after their initial inocu-

Table 1. Infectivity and symptomatology of LMV-Cr in selected indicator plants ${ }^{\mathrm{a}}$

\begin{tabular}{|c|c|c|}
\hline Host & Symptoms & ELISA $^{\text {b }}$ or PCR detection \\
\hline Catharanthus roseus & Mosaic & ELISA+ $(0.486 \pm 0.008)$ \\
\hline Zinnia elegans & Vein clearing & ELISA+ $(0.284 \pm 0.009)$ \\
\hline Chenopodium amaranticolor & Chlorotic spots & ELISA+ $(0.498 \pm 0.005)$ \\
\hline Chenopodium quinoa & Chlorotic spots & ELISA $+(0.415 \pm 0.007)$ \\
\hline Nicotiana benthamiana & Mosaic, wrinkled leaves & ELISA $+(0.356 \pm 0.027)$ \\
\hline Nicotiana clevelandii & Mosaic, wrinkled leaves & ELISA+ $(0.327 \pm 0.016)$ \\
\hline Chicorium endivia (escarole) & Chlorotic and necrotic spots, mosaic & ELISA+ $(0.377 \pm 0.015)$ \\
\hline Lactuca sativa (lettuce cv. Trocadéro) & Light mosaic & PCR+ \\
\hline Pisum sativum (pea, several cvs.) & Chlorotic spots & PCR+ \\
\hline
\end{tabular}

${ }^{a}$ Species tested but for which no symptoms or viral accumulation were observed: pepper (Capsicum annuum), eggplant (Solanum melongena), Vigna sinensis, Crambe cordifolia, melon (Cucumis melo), tobacco (Nicotiana tabaccum cv. Xanthi), tomato (Solanum lycopersicum cv. Momor), faba bean (Vicia faba), basil (Ocimum basilicum), Petunia hybrida, Datura stramonium, Physalis floridana, Lavatera trimestris, and Capsella bursa-pastoris.

${ }^{\mathrm{b}}$ For enzyme-linked immunosorbent assay (ELISA) detection, the optical density at $405 \mathrm{~nm} 2 \mathrm{~h}$ after substrate addition is given in parentheses together with the standard deviation. The corresponding average value for healthy control plants was 0.003 . PCR = polymerase chain reaction. 
lation, one LMV-AF199-inoculated plant developed infection symptoms. RT-PCR re-analysis of this plant now showed unambiguous virus accumulation (results not shown) and sequencing of the amplified cDNA confirmed the presence of LMVAF199. Retro-inoculation of this isolate to further $C$. roseus plants demonstrated that it now infected $92 \%$ of the inoculated C. roseus plants, while the parental LMV-AF199 failed to do so in parallel experiments (Table 2). This result was confirmed in two other independent inoculation experiments in which the same variant infected 93 and $100 \%$ of the inoculated C. roseus plants (not shown), demonstrating that a $C$. roseus-adapted variant of LMV-AF199 had indeed been selected, to which the name LMV-AF199-CRVar1 was given.

Efforts were then undertaken to try to select additional $C$. roseus-adapted variants of LMV-AF199. In two independent large-scale inoculation experiments, a total of 132 C. roseus plants were inoculated. In the first experiment, 44 plants were inoculated and monitored for 7 months but failed to develop any infection (results not shown). In the second experiment, 88 $C$. roseus plants were inoculated twice at a 1-month interval to try to improve the chances of recovering variants. Indeed, two variants were finally recovered following symptom development in two of the inoculated plants at 82 and 105 days postinoculation (not shown). These variants were given the names LMV-AF199-CRVar2 and -CRVar3.

\section{Analysis of mutations accumulated in LMV-AF199-CRVar1,} the Catharanthus roseus adapted variant.

The complete genomic sequences of the LMV-AF199CRVar1 variant and of its parental LMV-AF199 isolate were then determined using the same Illumina deep-sequencing strategy as described above for LMV-Cr. The sequencing yielded respectively 115,462 viral reads (70.2\% of total reads) and 69,306 viral reads (37\% of total reads) for these two isolates, corresponding to an average sequencing depth of, respectively, $807 \times$ and $484 \times$ (not shown).

As compared with the initially determined sequence of the LMV-AF199 isolate deposited in 2005 in GenBank (AJ278854; Krause-Sakate et al. 2005), the sequence determined for the parental LMV-AF199 isolate (GenBank KF268954) used in the present experiments differed at nine positions (Table 3). Of those, mutations at genome positions 79, 631, 4,690, and 7,117 are silent, while the five other mutations introduce changes in the encoded proteins.

The LMV-AF199-CRVar1 variant (GenBank KF268955) is identical to its parental LMV-AF199 isolate in seven of these nine positions, while it is identical to the database LMVAF199 sequence determined in 2005 at the last two positions (nt 5,930 and 7,117), one of which, at nucleotide 5,930, introduces an asparagine $(\mathrm{N})$ to aspartate (D) mutation in the C-terminus of the CI helicase (Table 3). In addition, the CRVar1 variant differs from its parental isolate at a further five positions, two of which are noncoding (nt 1,249 and 1,477) and three of which, at genome positions 6,360,6,593, and 6,597, respectively, introduce mutations at positions 65 ( $\mathrm{Y}$ to $\mathrm{F}$ ), 143 ( $\mathrm{S}$ to $\mathrm{P}$ ), and 144 (C to Y) of the VPg (Table 3). Remarkably, when analyzing the four coding mutations separating the $C$. roseus-adapted variant from its parental LMV-AF199 isolate, the LMV-Cr isolate is similar to the 2005 LMV-AF199 sequence in one of them (genome position 5,930) but has the same mutations as the variant at positions 65 and 143 of the VPg and has another amino acid, a leucine, at position 144 of the VPg (Table 3). Targeted sequencing of the LMV-AF199 parent following six serial passages in lettuce (GenBank KF285927 and KF285930) showed that it remained identical to the parental sequences at

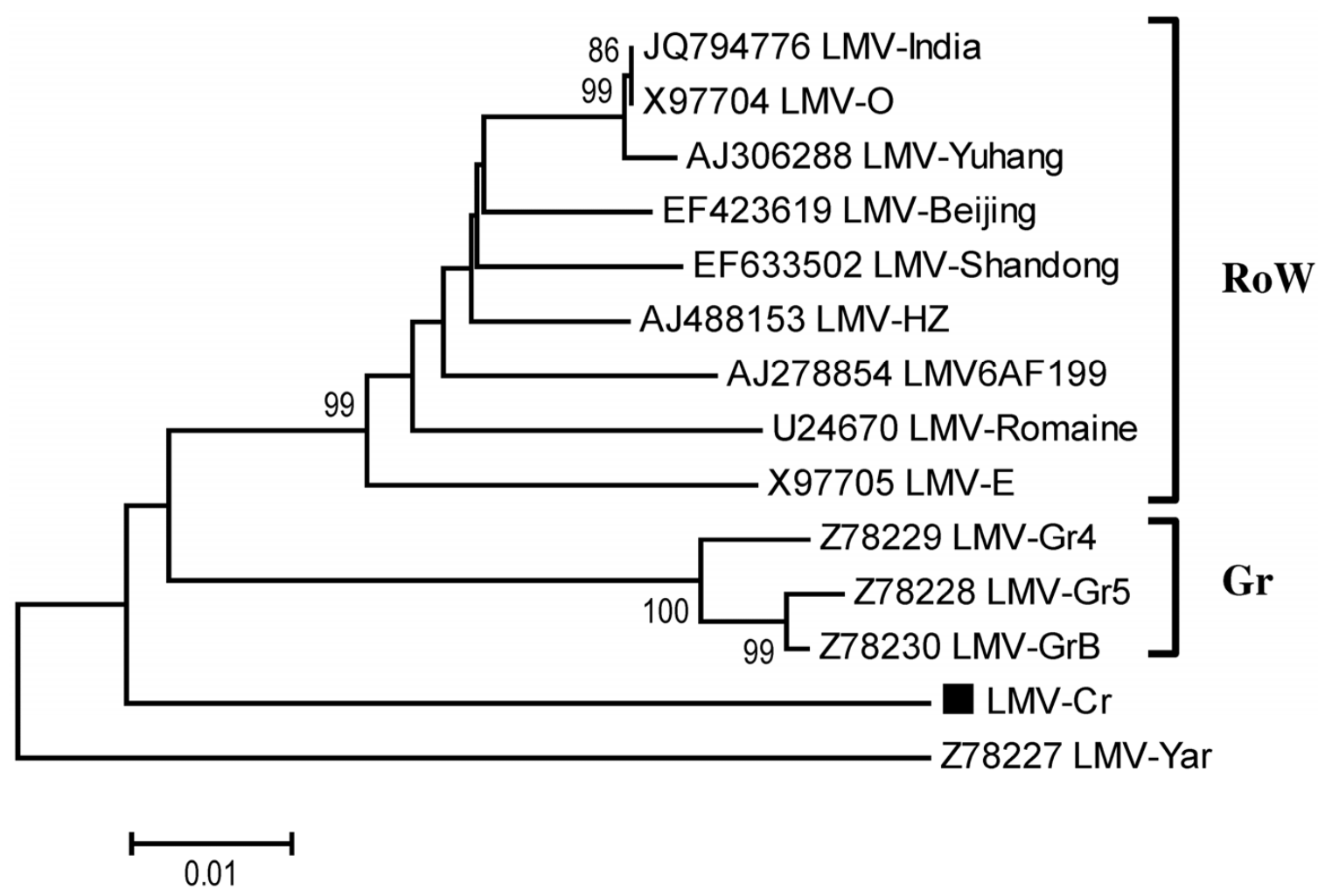

Fig. 1. Unrooted phylogenetic tree calculated from the sequence of the coat protein gene of Lettuce mosaic virus (LMV) isolates. The isolate names and sequence accession numbers are indicated and the LMV-Cr isolate is indicated by a black square. The tree was constructed by the neighbor-joining technique from strict nucleotide identity distances and the statistical significance of branches was evaluated by bootstrap analysis (1,000 replicates). Only bootstrap values greater than $70 \%$ are indicated. The scale bar represents $1 \%$ nucleotide divergence. Major clusters of LMV isolates are shown on the right. 
five of the seven positions at which the CRVar1 variant had diverged. However, at positions 5,930 $(\mathrm{A}>\mathrm{G})$ and 7,117 $(\mathrm{T}>\mathrm{C})$, it was observed to accumulate the same mutations observed in CRVar1 and also observed in the LMV-AF199 2005 database sequence (Table 3 ).

\section{Identification of mutations consistently associated with adaptation to $C$. roseus.}

Partial targeted sequencing of the genome of the two other C. roseus-adapted variants, CRVar2 (GenBank KF285928 and KF285931) and CRVar3 (GenBank KF285929 and KF285932), was then performed in order to try to identify mutations that had been independently selected during adaptation to this new host. The sequence and annealing conditions of the three primer pairs used for this partial resequencing effort are provided in Supplementary Table S2. A single new variable position was identified in LMV-AF199-CRVar3 at nt 1,247, causing an E to $\mathrm{K}$ amino-acid mutation at position 382 of the $\mathrm{P} 1$ protein (Table 3 ). Out of the seven surveyed positions at which LMV-AF199CRVar1 differed from its parent, only two, at positions 5,930 and 6,593, showed the same mutational pattern in all three analyzed $C$. roseus-adapted variants (Table 3 ). However, the coding mutations affecting the two other positions of the VPg were independently observed in one of the additional variants, mutation C6360T (VPg 65 Y to F) in variant CRVar2 and mutation G6597A (VPg 144 C to Y) in variant CRVar3 (Table 3).

\section{LMV-driven expression of lettuce eIF4E does not restore susceptibility of $C$. roseus to a nonadapted LMV isolate.}

In many potyvirus-plant pathosystems, including the LMVlettuce system (Nicaise et al. 2003), susceptibility has been associated with particular alleles of eIF4E or its isoform, eIF(iso)4E, and with an ability of the viral VPg to physically interact with these host factors (Kang et al. 2005; Leonard et al. 2000; Schaad et al. 2000; Wittmann et al. 1997). The finding that adaptation of LMV-AF199 to C. roseus was reproducibly associated with the accumulation of coding mutations in the viral VPg then prompted experiments to evaluate whether expression of a suitable eIF4E allele could restore susceptibility of C. roseus to a nonadapted LMV isolate.

A recombinant LMV-0 isolate expressing the $\mathrm{mol}^{0}$ (susceptible) form of lettuce eIF4E (German-Retana et al. 2008b; Nicaise et al. 2003) was inoculated in parallel to $C$. roseus plants and to LMV-resistant plants expressing the $\mathrm{mol}^{l}$ resistance allele in two independent experiments. As expected, expression of the $m o l^{0}$ allele from the viral genome complemented the resistant lettuce and allowed the recombinant virus to develop a symptomatic systemic infection in $100 \%$ of the inoculated resistant lettuce plants, unlike a nonrecombinant parental LMV-0 isolate (Nicaise et al. 2003). In contrast, neither the recombinant virus nor its nonrecombinant parent were able to infect the inoculated C. roseus plants, as demonstrated by the absence of symptoms and by the inability to detect the viral genome by RT-PCR in inoculated or in noninoculated leaves (not shown).

\section{DISCUSSION}

The results reported here demonstrate that, although it is not a host plant for a range of LMV isolates, C. roseus can be readily infected by the divergent $\mathrm{LMV}-\mathrm{Cr}$ isolate. The discovery of this isolate in a greenhouse in which, to our knowledge, no LMV had ever been introduced or manipulated, suggests that LMV-Cr could be seed-transmitted in this host, providing an explanation for the outbreak. In keeping with this idea, a second LMV isolate, closely related to LMV-Cr, was recently observed in the same greenhouse in a plant grown from seeds of the same origin.

The diversity of LMV has been demonstrated to be structured in a major "RoW" cluster of limited variability and into two much more restricted clusters (YAR and Gr) that are widely divergent from the RoW isolates but also from each other (Krause-Sakate et al. 2002; Revers et al. 1997a). The

Table 2. Symptomatology at 28 days postinoculation of Catharanthus roseus and lettuce plants inoculated with LMV-AF199 and with the C. roseus-adapted variant LMV-AF199-CRVar1

\begin{tabular}{lccc}
\hline & \multicolumn{2}{c}{ Number of symptomatic/number of inoculated plants } \\
\cline { 2 - 4 } LMV isolate & C. roseus & Lettuce cv. Mantilia (resistant, mol $^{\mathbf{l}}$ ) & Lettuce cv. Salinas 88 (resistant, mol $^{2}$ ) \\
\hline LMV-AF199 & $0 / 13$ & $4 / 4$ & $4 / 4$ \\
LMV-AF199-CRVar1 & $11 / 12$ & $4 / 4$ & $3 / 4$ \\
\hline
\end{tabular}

Table 3. Nucleotide sequence and encoded amino acid changes for various Lettuce mosaic virus (LMV) isolates or variants ${ }^{\mathrm{a}}$

\begin{tabular}{|c|c|c|c|c|c|c|c|c|c|c|c|c|c|c|}
\hline \multirow[b]{2}{*}{ Isolate or variant } & \multirow{2}{*}{$\frac{5^{\prime} \mathrm{NCR}}{79 / \mathrm{na}^{\mathrm{b}}}$} & \multicolumn{4}{|c|}{ P1 } & \multirow{2}{*}{$\frac{\text { HcPro }}{1,477 / \text { na }}$} & \multirow{2}{*}{$\frac{P 3}{3,411 / 208}$} & \multicolumn{3}{|c|}{ CI } & \multicolumn{3}{|c|}{ VPg } & \multirow{2}{*}{$\frac{\text { NIb }}{7,117 / \mathrm{na}}$} \\
\hline & & 631/na & $776 / 225$ & $819 / 239$ & $1,249 /$ na & & & $4,690 / \mathrm{na}$ & $5,930 / 618$ & $5,991 / 638$ & $6,360 / 65$ & $6,593 / 143$ & $6,597 / 144$ & \\
\hline \multicolumn{15}{|l|}{ LMV-AF199 } \\
\hline AJ278854 & $\mathrm{C}$ & $\mathrm{T}$ & $\mathrm{T}(\mathrm{S})$ & $\mathrm{G}(\mathrm{G})$ & A & G & $\mathrm{T}(\mathrm{L})$ & $\mathrm{C}$ & $G(D)$ & $\mathrm{T}(\mathrm{V})$ & $\mathrm{A}(\mathrm{Y})$ & $\mathrm{T}(\mathrm{S})$ & $\mathrm{G}(\mathrm{C})$ & $C$ \\
\hline LMV-AF199 & & & & & & & & & & & & & & \\
\hline parent & $\mathrm{G}$ & $\mathrm{C}$ & $\mathrm{C}(\mathrm{P})$ & $\mathrm{T}(\mathrm{V})$ & A & G & $\mathrm{C}(\mathrm{S})$ & $\mathrm{T}$ & $\mathrm{A}(\mathrm{N})$ & A (D) & $\mathrm{A}(\mathrm{Y})$ & $\mathrm{T}(\mathrm{S})$ & $\mathrm{G}(\mathrm{C})$ & $\mathrm{T}$ \\
\hline LMV-AF199 & nd & nd & nd & nd & A & G & nd & nd & $G(D)$ & nd & $\mathrm{A}(\mathrm{Y})$ & $\mathrm{T}(\mathrm{S})$ & $\mathrm{G}(\mathrm{C}$ & $C$ \\
\hline $\begin{array}{l}\text { LMV-AF199- } \\
\text { CRVar1 }\end{array}$ & $\mathrm{G}$ & $\mathrm{C}$ & $\mathrm{C}(\mathrm{P})$ & $\mathrm{T}(\mathrm{V})$ & $G$ & $\boldsymbol{A}$ & $\mathrm{C}(\mathrm{S})$ & $\mathrm{T}$ & $G(D)$ & A (D) & $T(F)$ & $C(P)$ & $A(Y)$ & $C$ \\
\hline LMV-AF199- & & & & & & & & & & & & & & \\
\hline CRVar2 & nd & nd & nd & nd & A & G & nd & nd & $G(D)$ & nd & $T(F)$ & $C(P)$ & $\mathrm{G}(\mathrm{C})$ & $C$ \\
\hline CRVar3 & nd & nd & nd & nd & $A^{d}$ & G & nd & nd & $G(D)$ & nd & $\mathrm{A}(\mathrm{Y})$ & $C(P)$ & $A(Y)$ & $C$ \\
\hline $\mathrm{LMV} \mathrm{Cr}$ & $\mathrm{A}$ & $\mathrm{T}$ & $\mathrm{C}(\mathrm{P})$ & $\mathrm{G}(\mathrm{G})$ & $\mathrm{A}$ & G & $\mathrm{C}(\mathrm{S})$ & $\mathrm{T}$ & $G(D)$ & A & $T(F)$ & $C(P)$ & $\mathrm{T}(\mathrm{L})^{\mathrm{e}}$ & $\mathrm{T}$ \\
\hline
\end{tabular}

a If a nucleotide mutation causes an amino acid (aa) change, the corresponding aa is indicated in parentheses. The nucleotide numbering is according to the genome sequence of LMV-0 (X97704). The amino acids are numbered according to the sequence of each mature protein in the genome of LMV-0. Mutations that differentiate the Catharanthus roseus-adapted variant LMV-AF199-CRVar1 from it parental isolate LMV-AF199 are indicated in bold italics. na = does not apply; nd = not determined.

b Nucleotide/amino acid positions.

c $6 \times$ lettuce passaged.

${ }^{\mathrm{d}}$ An additional $\mathrm{G}>\mathrm{A}$ mutation at position 1,247 causes an $\mathrm{E}>\mathrm{K}$ amino acid exchange at $\mathrm{P} 1$ protein aa position 382.

e Additional $\mathrm{T}>\mathrm{C}$ and $\mathrm{C}>\mathrm{T}$ mutations at positions 6,592 and 6,594 cause a $\mathrm{C}>\mathrm{L}$ amino acid exchange at VPg aa position 144 . 
LMV-Cr isolate appears to represent a third divergent cluster (Fig. 1), which may find its origin in South America, since the seed lots associated with the outbreak were tentatively traced back to this region.

Given the wide divergence between LMV-Cr and other $\mathrm{LMV}$ isolates, it is not possible to pinpoint sequence elements endowing it with the ability to infect $C$. roseus, a nonhost plant for the three LMV isolates of the RoW cluster that were analyzed in the present work. Although it was not possible to obtain isolates adapted to this plant from the LMV-0 and LMV-E isolates, such adapted variants could be isolated at a low frequency and after several months delay for the LMV-AF199 parent. The fact that the variants emerged up to several months following the initial inoculation suggests that despite the negative RT-PCR results, the virus was able to replicate at a very low level during this period, possibly allowing for the generation and accumulation of adaptive mutations.

Overall, seven positions were identified as differing in at least some of the C. roseus-adapted variants from the parental AF199 sequences. Of these, three are noncoding (positions $1,249,1,477$, and 7,117) and only at position 7,117 did all three variants accumulate the same $\mathrm{T} 7117 \mathrm{C}$ mutation. Besides its noncoding character, this mutation is, however, unlikely to contribute to adaptation to the $C$. roseus host since i) it was observed in the original LMV-AF199 2005 sequence (and in the LMV-AF199 isolate itself following six passages in lettuce), and ii) it is absent from the LMV-Cr isolate.

The four other identified mutations generate changes in the encoded proteins, and two of them were observed to be shared by all three adapted variants. The A5930G mutation is potentially interesting, as it causes an $\mathrm{N}$ to $\mathrm{D}$ mutation at position 618 of the C-terminus of the CI helicase, a region that has been identified as important for overcoming the mol resistance in lettuce (Abdul-Razzak et al. 2009). However, the sequence observed in the variants is similar to the LMV-AF199 2005 sequence and to that of the LMV-AF199 isolate following six passages in lettuce (Table 3), indicating that fluctuation at this position occurs in LMV-AF199 independently of the selection pressure exerted by $C$. roseus. Therefore, we cannot rule out the possibility that the accumulation of the A5930G mutation in all three $C$. roseus-adapted variants could be coincidental or could merely reflect the counter-selection of a deleterious mutation present in the particular parental stock used.

More remarkable is the T6593C mutation, which causes a serine to proline change at position 143 of the VPg and is independently observed in all three variants and in the $\mathrm{LMV}-\mathrm{Cr}$ isolate. Taken together, these observations provide very strong support to the hypothesis that this mutation in the central domain of the VPg contributes directly to adaptation of LMV to C. roseus. A wide range of viral proteins have been shown or suggested to contribute to adaptation of potyviruses to their host plants (Carbonnel et al. 2012; Chen et al. 2008; Salvador et al. 2008a and b; Suehiro et al. 2004; Tan et al. 2005; Tatineni et al. 2011; Wallis et al. 2007). However, the VPg has been implicated in this respect in a single study (Tan et al. 2005) that analyzed several independent lineages of TuMV after serial passaging in Raphanus sativus and showed accumulation of mutations in the VPg at a position equivalent to LMV VPg position 148, in close proximity to position 143 identified in the present work.

The case for the other two identified mutations in the VPg is somewhat less convincing but still puzzling. Mutation A6360T (Y65F) is independently observed in variants CRVar1 and CRVar2 and also in LMV-Cr, while mutation G6597A, which affects the amino acid adjacent to position VPg 143 identified above (C144Y), is independently observed in variants CRVar1 and CRVar3, while a leucine is found at the same position in the VPg of the LMV-Cr isolate (Table 3). These results do not allow a firm conclusion but could suggest that mutations at one or both positions 65 or 144 could also be implicated, in conjunction with the $\mathrm{S} 143 \mathrm{P}$ mutation, in adaptation to $C$. roseus in a fashion reminiscent of the complex accumulation of mutations involved in resistance breaking in some potyvirusplant interactions (Ayme et al. 2007).

Taken together, the results reported here pinpoint the contribution of the central portion of the VPg and, possibly, of the Cterminal region of the CI helicase in adaptation of LMV to the nonhost plant $C$. roseus. Given that these genomic regions are also involved in the overcoming of eIF4E-mediated resistance in lettuce (Abdul-Razzak et al. 2009), it was a logical step to evaluate whether transient expression of lettuce eIF4E could allow LMV replication and spread in C. roseus. The negative result obtained seems to rule against this hypothesis, but other elements might explain this negative result, e.g., a need for a proper interaction between the expressed lettuce eIF4E and other $C$. roseus factors, such as the eIF4G, which has been shown to be recruited by potyviruses in a coordinated fashion with eIF4E (Nicaise et al. 2007).

Further work involving both site-directed mutagenesis of infectious cDNA clones is now needed to clarify one or more roles of individual mutations in LMV adaptation to $C$. roseus and, more importantly, to identify the plant components restricting the multiplication and spread of nonadapted LMV variants in this plant.

\section{MATERIALS AND METHODS}

\section{Virus isolates and inoculation assays.}

The lettuce isolates LMV-0, LMV-E, and LMV-AF199 have been previously described (Krause-Sakate et al. 2002; Revers et al. 1997a). The isolate LMV-Cr was isolated from a symptomatic Madagascar periwinckle plant. All isolates were mechanically inoculated (Revers et al. 1997a) and the plants were kept in a standard greenhouse. The appearance of symptoms on the upper noninoculated leaves was observed at weekly intervals. When needed, isolates were kept, either as frozen infected leaves $\left(-20^{\circ} \mathrm{C}\right.$ or $\left.-80^{\circ} \mathrm{C}\right)$ or as infected tissue desiccated over anhydrous $\mathrm{CaCl}_{2}$. The following lettuce varieties were used: Trocadéro $\left(m o l^{0}\right.$, susceptible), Mantilia (resistant, $m o l^{l}$ ), or Salinas88 (resistant, $\mathrm{mol}^{2}$ ).

\section{Enzyme-linked immunosorbent assay (ELISA) or RT-PCR detection of LMV.}

LMV presence was assessed by double-antibody sandwichELISA using polyclonal rabbit antibodies raised against purified LMV virions (Candresse et al. 2007). Alternatively, RTPCR using the NIb-P4 primer pair (Revers et al. 1999) was performed on total nucleic acid extracts, and the resulting amplified fragment $(278 \mathrm{nt})$ was analyzed by nondenaturing agarose gel electrophoresis, followed by ethidium bromide staining and, when needed, directly sequenced on both strands (Beckman Coulter Genomics, Grenoble, France).

\section{Determination of LMV full-length genomic sequences by Illumina deep sequencing.}

For the immunocapture of viral particles, the protocol from Revers and associates (1997a) was used except that infected lettuce or periwinckle leaves were homogenized 1:4 (wt/vol) in grinding buffer before being incubated overnight at $4{ }^{\circ} \mathrm{C}$ in $0.5-\mathrm{ml}$ tubes precoated with anti-LMV immunoglobulins (2 $\mu \mathrm{g} / \mathrm{ml})$. The tubes were then washed five times with phosphate buffered saline.

The encapsidated viral RNAs were denatured, adding 32.2 $\mu \mathrm{l}$ of water during $2 \mathrm{~min}$ at $95^{\circ} \mathrm{C}$ and the tubes were immersed 
in ice, and then, $0.8 \mu \mathrm{M}$ PcDNA $_{12}\left(5^{\prime}\right.$ TGTGTTGGGTGTG TTTGGN $_{12} 3^{\prime}$ ) and $0.2 \mathrm{mM}$ dNTPs were added, followed by $5 \mathrm{~min}$ at $95^{\circ} \mathrm{C}$ and the tubes were returned to the ice. RT was performed in a 50- $\mu$ l final volume using the SuperscriptII reverse transcriptase according to the manufacturer's instructions (Invitrogen, Carlsbad, CA, U.S.A.). The resulting cDNAs were then submitted to a whole-genome amplification procedure, allowing, at the same time, their conversion to double-stranded cDNA and their tagging with 8-bp multiplex identifier (MID) tags to allow their pooled sequencing. Complementary DNA was amplified using $5 \mu \mathrm{l}$ of RT products in a $50-\mu \mathrm{l}$ reaction containing $1 \times$ reaction buffer, $0.25 \mathrm{mM}$ dNTPs, $1 \mu \mathrm{M}$ of primer (5' AACCGCAATGTGTTGGGTGTGTTTGG 3', example of MID tag in bold italics) and $0.5 \mathrm{U}$ of DyNAzym II DNA polymerase (Finnzymes, Espoo, Finland). Amplifications were performed as follows: $94^{\circ} \mathrm{C}$ for $1 \mathrm{~min} ; 65^{\circ} \mathrm{C}$ for $0 \mathrm{~s} ; 72^{\circ} \mathrm{C}$ for $45 \mathrm{~s}$, with a slope of $5^{\circ} \mathrm{C}$ per s, followed by 40 cycles of $94^{\circ} \mathrm{C}$ for $0 \mathrm{~s} ; 45^{\circ} \mathrm{C}$ for $0 \mathrm{~s} ; 72^{\circ} \mathrm{C}$ for $5 \mathrm{~min}$, with the same slope, and final steps of $5 \mathrm{~min}$ at $72^{\circ} \mathrm{C}$ and $5 \mathrm{~min}$ at $37^{\circ} \mathrm{C}$. After removal of primers using the MinElute PCR purification kit (Qiagen, Hilden, Germany), the concentration of the amplification products was determined spectrophotometrically, and $150 \mathrm{ng}$ of PCR products were pooled with the amplified material from 50 other viral templates (discussed below) to be analyzed (100 nt, paired ends sequencing), using one lane of an Illumina GAIIx flow cell.

\section{Illumina data manipulation, assembly, and annotation.}

All analyses and manipulation of Illumina sequencing data were performed using CLC Genomics Workbench 5.1. Sequencing reads were first demultiplexed in order to assign individual reads to the relevant sample. The adaptors containing the multiplexing tags were removed from the reads, which were then screened and trimmed on quality. Reads were finally assembled in contigs and scaffolds, using a combination of de novo assembly and mapping on a LMV full-length reference genome (LMV-0, X97704).

\section{Targeted polishing and confirmation of LMV isolates of variant genomic sequences.}

The few gaps between the contigs obtained from the Illumina sequences and targeted regions for which sequence confirmation was sought were amplified from the relevant LMV isolate, with primers designed from the contigs using $5 \mu \mathrm{l}$ of the cDNAs synthesized for the Illumina deep sequencing. The $50-\mu \mathrm{l}$ reactions contained $0.2 \mu \mathrm{M}$ of each primer and $1 \mu \mathrm{l}$ of $50 \times$ Advantage 2 Polymerase mix, according to the manufacturer's recommendations (Clontech, Mountain View, CA, U.S.A.). All amplification products were confirmed by nondenaturing agarose gel electrophoresis before being sequenced (Beckman Coulter Genomics). The sequences obtained were finally assembled with the Illumina contigs to generate the complete genomic sequence of the various LMV isolates.

\section{Targeted sequencing of the genome of LMV variants.}

For all RT-PCR assays, a cDNA initiated by pdN6 and oligodT18 primers was synthesized from $5 \mu$ of total nucleic acids, using SupercriptII reverse transcriptase according to the manufacturer's recommendations (Invitrogen). In a second step, the PCR was carried out using the same protocol as described to validate the Illumina data. All amplification products were directly sequenced on both strands (Beckman Coulter Genomics).

\section{Sequence comparisons and phylogenetic analyses.}

Multiple alignments of nucleotide or amino acid sequences were performed using the ClustalX program (Thompson et al.
1997) as implemented in Mega 5.0 (Tamura et al. 2011). Pairwise strict nucleotide and amino acid distances were computed using Mega 5.0, and phylogenetic trees were reconstructed using the neighbor-joining algorithm in Mega 5.0.

\section{In planta transient expression}

of a permissive form of lettuce eIF4E

through the use of a recombinant $\mathrm{LMV}$ isolate.

The recombinant LMV-0 isolate with the Ls-eIF4E cDNA (Lactuca sativa eIF4E) inserted in frame between the $\mathrm{P} 1$ and Hc-Pro domains, with an NIa-Pro cleavage site resulting in the addition of eight amino acids (PGDEVYHQ) at the $\mathrm{C}$ terminus of the eIF4E sequence has been described previously (Nicaise et al. 2003). Lettuce plants were initially inoculated by biolistics with the infectious cDNA clone and the recombinant isolate was then mechanically inoculated to test plants as described above.

\section{ACKNOWLEDGMENTS}

The authors thank A. Bailly, T. Mauduit, and K. Guionneaud for taking care of experimental plants. The help of the staff of the Génome-Transcriptome platform of the Centre de Génomique Fonctionnelle of Bordeaux for the Illumina sequencing is gratefully acknowledged.

\section{LITERATURE CITED}

Abdul-Razzak, A., Guiraud, T., Peypelut, M., Walter, J., Houvenaghel, M. C., Candresse, T., Le Gall, O., and German-Retana, S. 2009. Involvement of the cylindrical inclusion (CI) protein in the overcoming of an eIF4E-mediated resistance against Lettuce mosaic potyvirus. Mol. Plant Pathol. 10:109-113.

Anderson, P. K., Cunningham, A. A., Patel, N. G., Morales, F. J., Epstein, P. R., and Daszak, P. 2004. Emerging infectious diseases of plants: Pathogen pollution, climate change and agrotechnological drivers. Trends Ecol. Evol. 19:535-544.

Ayme, V., Souche, S., Caranta, C., Jacquemond, M., Chadoeuf, J., Palloix, A., and Moury, B. 2006. Different mutations in the genome linked protein VPg of Potato virus $Y$ confer virulence on the $p v r 2^{3}$ resistance in pepper. Mol. Plant-Microbe Interact. 19:557-563.

Ayme, V., Petit-Pierre, J., Souche, S., Palloix, A., and Moury, B. 2007. Molecular dissection of the Potato virus Y VPg virulence factor reveals complex adaptations to the pvr2 resistance allelic series in pepper. J. Gen. Virol. 88:1594-1601.

Borgstrom, B., and Johansen, I. E. 2001. Mutations in Pea seedborne mosaic virus genome-linked protein VPg after pathotype-specific virulence in Pisum sativum. Mol. Plant-Microbe Interact. 14:707-714.

Candresse, T., Lot, H., German-Retana, S., Krause-Sakate, R., Thomas, J. Souche, S., Delaunay, T., Lanneau, M., and Le Gall, O. 2007. Analysis of the serological variability of Lettuce mosaic virus using monoclonal antibodies and surface plasmon resonance technology. J. Gen. Virol. 88:2605-2610.

Carbonell, A., Dujovny, G., García, J. A., and Valli, A. 2012. The Cucumber vein yellowing virus silencing suppressor $\mathrm{P} 1 \mathrm{~b}$ can functionally replace HCPro in Plum pox virus infection in a host-specific manner. Mol. Plant-Microbe Interact. 25:151-164.

Chen, K.-C., Chiang, C.-H., Raja, J. A., Liu, F.-L., Tai, C.-H., and Yeh, S.-D. 2008. A single amino acid of niapro of Papaya ringspot virus determines host specificity for infection of papaya. Mol. Plant-Microbe Interact. 21:1046-1057.

Dinant, S., and Lot, H. 1992. Lettuce mosaic virus: A review. Plant Pathol. 41:528-542.

German-Retana, S., Walter, J., and Le Gall, O. 2008a. Lettuce mosaic virus: From pathogen diversity to host interactors. Mol. Plant Pathol. 9:127-136.

Horvath, J. 1980. Viruses of lettuce. II. Host range of Lettuce mosaic virus and Cucumber mosaic virus. Acta Agron. Acad. Sci. Hungar. 29:333352.

Jones, R. A. C. 2009. Plant virus emergence and evolution: Origins, new encounter scenarios, factors driving emergence, effects of changing world conditions, and prospects for control. Virus Res. 141:113-130.

Kang, B. C., Yeam, I., Frantz, J. D., Murphy, J. F., and Jahn, M. M. 2005. The pvr1 locus in Capsicum encodes a translation initiation factor eIF4E that interacts with Tobacco etch virus VPg. Plant J. 42:392-405.

Krause-Sakate, R., Le Gall, O., Fakhfakh, H., Peypelut, M., Marrakchi, M., Varveri, C., Pavan, M. A., Souche, S., Lot, H., Zerbini, F. M., and 
Candresse, T. 2002. Molecular characterization of Lettuce mosaic virus field isolates reveals a distinct and widespread type of resistance-breaking isolate: LMV-Most. Phytopathology 92:563-572.

Krause-Sakate, R., Redondo, E., Richard-Forget, F., Jadao, A. S., Houvenaghel, M. C., German-Retana, S., Pavan, M. A., Candresse, T., Zerbini, F. M., and Le Gall, O. 2005. Molecular mapping of the viral determinants of systemic wilting induced by a Lettuce mosaic virus (LMV) isolate in some lettuce cultivars. Virus Res. 109:175-180.

Le Gall, O. 2003. Lettuce mosaic virus. Page 399 in: Description of Plant Viruses. A. T. Jones, D. J. Robinson, N. Boonham, and R. Mumford, eds. Commonwealth Mycological Institute-Association of Applied Biologists, Wellesbourne, U.K.

Leonard, S., Plante, D., Wittmann, S., Daigneault, N., Fortin, M. G., and Laliberte, J. F. 2000. Complex formation between potyvirus VPg and translation eukaryotic initiation factor $4 \mathrm{E}$ correlates with virus infectivity. J. Virol. 74:7730-7737.

Maciel, S. C., Ferreira da Silva, R. Reis, M. S., Jadão, A. S., Rosa, D. D., Giampan, J. S., Kitajima, E. W., Marques Rezende, J. A., and Aranha Camargo, J. E. 2011. Characterization of a new potyvirus causing mosaic and flower variegation in Catharanthus roseus in Brazil. Sci. Agric. 68:687-690.

Moury, B., Morel, C., Johansen, E., Guilbaud, L., Souche, S., Ayme, V., Caranta, C., Palloix, A., and Jacquemond, M. 2004. Mutations in potato virus $\mathrm{Y}$ genome-linked protein determine virulence toward recessive resistances in Capsicum annuum and Lycopersicon hirsutum. Mol. Plant-Microbe Interact. 17:322-329.

Nicaise, V., German-Retana, S., Sanjuan, R., Dubrana, M. P., Mazier, M., Maisonneuve, B., Candresse, T., Caranta, C., and LeGall, O. 2003. The eukaryotic translation initiation factor 4E controls lettuce susceptibility to the potyvirus Lettuce mosaic virus. Plant Physiol. 132:12721282.

Nicaise, V., Gallois, J. L., Chafiai, F., Allen, L. M., Schurdi-Levraud, V., Browning, K. S., Candresse, T., Caranta, C., Le Gall, O., and GermanRetana, S. 2007. Coordinated and selective recruitment of eIF4E and eIF4G factors for potyvirus infection in Arabidopsis thaliana. FEBS (Fed. Eur. Biochem. Soc.) Lett. 581:1041-1046.

Parrish, C. R., Holmes, E. C., Morens, D. M., Park, E. C., Burke, D. S., Calisher, C. H., Laughlin, C. A., Saif, L. J., and Daszak, P. 2008. Crossspecies transmission and the emergence of new epidemic diseases. Microbiol. Mol. Biol. Rev. 72:457-470.

Revers, F., Lot, H., Souche, S., Le Gall, O., Candresse, T., and Dunez, J. 1997a. Biological and molecular variability of Lettuce mosaic virus isolates. Phytopathology 87:397-403.

Revers, F., Yang, S. J., Walter, J., Souche, S., Lot, H., Le Gall, O., Candresse, T., and Dunez, J. 1997b. Comparison of the complete nucle- otide sequences of two isolates of Lettuce mosaic virus differing in their biological properties. Virus Res. 47:167-177.

Revers, F., van der Vlugt, R. A. A., Souche, S., Lanneau, M., Lot, H., Candresse, T., and Le Gall, O. 1999. Nucleotide sequence of the 3'terminal region of the genome of four Lettuce mosaic virus isolates from Greece and Yemen. Arch. Virol. 144:1619-1626.

Salvador, B., Delgadillo, M. O., Saénz, P., García, J. A., and Simón-Mateo, C. 2008a. Identification of Plum pox virus pathogenicity determinant in herbaceous and woody hosts. Mol. Plant-Microbe Interact. 21:20-29.

Salvador, B., Saénz, P., Yangüez, E., Quiot, J. B., Quiot, L., Delgadillo, M. O., García, J. A., and Simón-Mateo, C. 2008b. Host-specific effect of P1 exchange between two potyviruses. Mol. Plant Pathol. 9:147-155.

Schaad, M. C., Anderberg, R. J., and Carrington, J. C. 2000. Strain-specific interaction of the Tobacco etch virus NIa protein with the translation initiation factor eIF4E in the yeast two-hybrid system. Virology 273:300306.

Suehiro, N., Natsuaki, T., Watanabe, T., and Okuda, S. 2004. An important determinant of the ability of Turnip mosaic virus to infect Brassica spp. and/or Raphanus sativus is in its P3 protein. J. Gen. Virol., 85:20872098.

Tamura, K., Peterson, D., Peterson, N., Stecher, G., Nei, M., and Kumar, S. 2011. MEGA5: Molecular evolutionary genetics analysis using maximum likelihood, evolutionary distance, and maximum parsimony methods. Mol. Biol. Evol. 28:2731-2739.

Tan, Z., Gibbs, A. J., Tomitaka, Y., Sánchez, F., Ponz, F., and Ohshima, K. 2005. Mutations in Turnip mosaic virus genomes that have adapted to Raphanus sativus. J. Gen. Virol. 86:501-510.

Tatineni, S., Van Winkle, D. H., and French, R. 2011. The N-terminal region of Wheat streak mosaic virus coat protein is a host- and strainspecific long-distance transport factor. J. Virol. 85:1718-1731.

Thompson, J. D., Gibson, T. J., Plewniak, F., Jeanmougin, F., and Higgins, D. G. 1997. The Clustal X windows interface: Flexible strategies for multiple sequence alignment aided by quality analysis tools. Nucleic Acids Res. 24:4876-4882.

Wallis, C. M., Stone, A. L., Sherman, D. J., Damsteegt, V. D., Gildow, F. E., and Schneider, W. L. 2007. Adaptation of Plum pox virus to a herbaceous host (Pisum sativum) following serial passages. J. Gen. Virol. 88:2839-2845.

Wittmann, S., Chatel, H., Fortin, M. G., and Laliberté, J. F. 1997. Interaction of the viral protein genome linked of Turnip mosaic potyvirus with the translational eukaryotic initiation factor (iso) 4E of Arabidopsis thaliana using the yeast two-hybrid system. Virology 234:84-92.

Woolhouse, M. E. J., Haydon, D. T., and Antia, R. 2005. Emerging pathogens: The epidemiology and evolution of species jumps. Trends Ecol. Evol. 20:238-244. 